\title{
Desplazamientos y gentrificación extendida. Políticas neoliberales y resistencias sociales en la Ciudad de México'
}

\author{
Patricia Olivera ${ }^{2}$ y Luis Salinas ${ }^{3}$
}

\begin{abstract}
RESUMEN
La reciente dinámica del sector inmobiliario en la Ciudad de México produce nuevas formas de gentrificación, siendo su principal soporte la transformación del Estado en agente facilitador del mercado inmobiliario y la decidida participación de la inversión financiera público-privada. Los intereses inmobiliarios dentro y fuera de las áreas centrales, sostenidos bajo la política "ciudad compacta", han derivado en gentrificación con desplazamientos sociales generalizados relacionados con la edificación intensiva y su encarecimiento. Se discuten las características de los grandes proyectos diseñados por agentes privados y público-privados y se desentrañan las estrategias neoliberales y las sinergias que contribuyen a la rentabilización de espacios interiores, en confrontación con las distintas formas de resistencia social ante los crecientes desplazamientos. Se ponen de relieve dos barrios: Norte de Polanco y Colonia Juárez, donde los residentes desafían el proyecto neoliberal gentrificador con acciones que contribuyen a la defensa del territorio y el derecho a la ciudad.
\end{abstract}

Palabras clave: Gentrificación extendida, Políticas urbanas neoliberales, Resistencia social, Gentrificación y desplazamiento, Defensa del territorio.

\begin{abstract}
The recent dynamics of the Real Estate sector in Mexico City influences new gentrification processes, having as the main support the State transformation as a facilitator agent of estate market jointly with the instrumental financial capital. The estate market interests within the city and suburbs expressed by the "Compact City" policy, have derived on gentrification and generalized social displacements related to the expensive and intensive edificability. The paper evidences the displacements induced by the private and publicprivate developers. It is also analysed the neoliberal conditions, strategies and synergies which contribute to the profitability of spaces within Mexico City, and its association with different and growing experiences of social resistance against displacements. Two districts are highlighted: North Polanco y Colonia Juárez, where residents have organized social actions against the neoliberal gentrification projects and towards the defense of territory and the right to the city.
\end{abstract}

Keywords: Extended gentrification, Neoliberal urban policies, Social resistance, Gentrification \& displacement, Defence of territory. 
La rearticulación de capitales inmobiliario y financiero es una de las aristas del papel crucial que juegan a escala mundial en la dinámica de acumulación y su imbricación en las relaciones sociales cotidianas a través de la circulación de los fondos de préstamo (Moreno, 2014:253). En la Ciudad de México en la última década esta articulación se ha profundizado y la política urbana neoliberal encuentra los hilos conductores para fijarse en el suelo urbano a través del organismo público-privado constituido como Agencia de Promoción y Desarrollo para la Ciudad de México (Procdmx), creada en 2007. Esta empresa lanzó en 2013 una propuesta de grandes proyectos urbanos denominados Zonas de Desarrollo Económico y Social (Zodes) en áreas de alto potencial de la ciudad que actualmente se hallan subutilizadas y donde se proyectaron desarrollos de servicios, habitacionales y comerciales de gran impacto económico. Esto ha propiciado procesos de desplazamiento social del espacio habitado derivado de la presión especulativa y la desposesión, material y simbólica, desplegándose condiciones que gestan acciones colectivas de resistencia frente a la subalternidad existente (Modonesi, 2014).

En América Latina se han realizado importantes trabajos sobre el papel del mercado inmobiliario urbano exclusionario. Destacan las aportaciones de Abramo (2011) y Jaramillo (2009) quienes expresan la transformación de la estructura intraurbana a partir de la racionalidad de mercado y la financiación de la lógica de rentabilización inmobiliaria en submercados formales de las ciudades latinoamericanas (Abramo, 2011: 99). En la Ciudad de México destaca el aporte pionero de Schteingart respecto al mercado de grandes conjuntos habitacionales privados, apoyados en la valorización de la tierra a partir de la especulación y rentas diferenciales (Schteingart, 1979:464). Fuera del interés de inmobiliarias e instituciones financieras, faltan estudios académicos recientes sobre las estrategias de los agentes del mercado del suelo, particularmente en la Ciudad de México, donde se incrementan los desarrollos de diversos usos y elevada intensidad de construcción. En el marco interpretativo crítico de la neoliberalización de la Ciudad de México nos planteamos desentrañar las estrategias que los impulsan, así como los efectos sociales que desencadenan, tales como la gentrificación extendida.

Las preguntas orientadoras del trabajo plantean ¿Cuáles son las estrategias del gobierno local y sus alianzas con agentes privados para el desarrollo inmobiliario en Ciudad de México? ¿Qué acciones sociales modificaron tales proyectos? Y también ¿Estas estrategias inmobiliarias neoliberales, de qué manera generalizan los procesos de exclusión? Se busca contribuir en la discusión teórica acerca de los mecanismos de gestión público-privada en la Ciudad de México partiendo de ejemplos de desarrollos excluyentes en dos barrios elegidos.

El artículo se divide en tres apartados, en el primero se discute el desarrollo inmobiliario asociado con la gentrificación extendida en la Ciudad de México. En el segundo se plantean los mecanismos de la política neoliberal pública-privada a partir de los proyectos urbanos impulsados por la agencia Procdmx. En el tercer apartado se discuten los procesos de desplazamiento de población existente en la colonia Juárez y las colonias Granadas. Se analizan documentos oficiales de la agencia Procdmx referentes a las promociones inmobiliarias en el Corredor Cultural Chapultepec y el Plan Maestro Granadas, las modificaciones de la normatividad de los programas urbanos en la última década y se detectaron los agentes inmobiliarios participantes. Se realizaron entrevistas semiestructuradas durante 2015 y $2016^{4}$ con vecinos de las colonias Juárez, Granada

Agradecemos a Lorena Rodríguez y a Emilio Romero su colaboración en las entrevistas realizadas entre julio de 2015 y febrero de 2016. 
y Torre Blanca en torno a las formas de resistencia ante esos proyectos que les aquejan y las acciones emprendidas.

\section{Políticas neoliberales en la Ciudad de México. Hacia una gentrificación extendida}

Con el triunfo de la fracción tecnócrata en 1982 en México comenzó la neoliberalización de la Ciudad de México con un patrón de desindustrialización acelerado y una profunda reestructuración social y económica volcada hacia los servicios profesionales y financieros (Olivera, 2014). Si bien la gentrificación de la ciudad se inició con la patrimonialización del Centro Histórico desde 1987 (una zona semi abandonada y degradada), articulando intereses públicos y privados para beneficiarse de la centralidad y el control político, fue en la década de 2000 cuando se aceleraron los ritmos de reactivación inmobiliaria en diversos barrios de la zona metropolitana. El Bando $2^{5}$ propició la edificación intensiva de los usos más rentables en las delegaciones centrales, multiplicándose los desarrollos habitacionales verticales para ingresos medios altos; se consolidaron los distritos, corredores concentradores de oficinas y centros comerciales para el consumo de bienes cada vez más diversificados, abriendo las puertas al capital financiero e inmobiliario. A pesar de su derogación en 2006, siguió una intensa demolición, reciclamiento y nuevas construcciones, particularmente donde se presentaron las condiciones de abandono, degradación y caída de la renta del suelo industrial y vivienda de clases trabajadoras, aunado a la precariedad e incertidumbre en la tenencia.

La gentrificación de la Ciudad de México durante la década de 2010 combina la elevación de los precios del suelo alrededor de áreas renovadas y gentrificadas con anterioridad en el Centro Histórico, Condesa y Santa Fe, con nueva oferta de promociones comerciales y habitacionales para clases medias y altas alentada con las Zodes ${ }^{6}$, aunado al desarrollo de nodos de transporte multimodal. Entre los nuevos proyectos inmobiliarios destacan el centro corporativo, comercial y de usos mixtos Plaza Carso y el Corredor Cultural Chapultepec, este último propuesto por la agencia Procdmx, ${ }^{7}$ entre otros diseminados en toda la ciudad, concesionados a privados, propiciando condiciones hacia una gentrificación extendida.

Los trabajos sobre gentrificación en ciudades latinoamericanas y de España se centran en tres perspectivas generales: i. Las formas simbólicas relacionadas con las políticas de patrimonio histórico de las ciudades y los movimientos de resistencia, en Buenos Aires y en Madrid existe una larga trayectoria de luchas en barrios afectados por políticas de renovación urbana (Rodríguez et al., 2015; Janoschka et al., 2014); ii. La gentrificación vinculada con la neoliberalización y los nuevos mercados inmobiliarios, aunado al desplazamiento de sectores tradicionales, de su vivienda y comercio (Olivera, 2013; Olivera y Delgadillo, 2014; Salinas, 2013 y 2014, Cócola et al.,

Bando de gobierno, ver Diario Oficial de Gobierno del Distrito Federal 17 de diciembre de 2000.

Son áreas de gestión estratégica definidas por Procdmex donde se aplicarían normatividades especiales para atraer inversión y densificar los usos. Las Zodes propuestas fueron Ciudad de la Salud (Tlalpan), la Ciudad de la Tecnología o del Futuro (Coyoacán), el Corredor Cultural Creativo-Chapultepec (Cuauhtémoc- Juárez), la Ciudad Verde o Agroindustrial (Azcapotzalco) y la Ciudad Administrativa (Cuauhtémoc-Doctores). Gaceta Oficial del Distrito Federal el 14 de diciembre de 2007. Inicialmente Calidad de Vida, Progreso y Desarrollo para la Ciudad de México, S.A. de C.V., en el marco de la Ley de Asociaciones Público- Privadas, se ostentada como agencia de promoción, inversión y desarrollo, conforma un poder paralelo al de la Asamblea Legislativa de la Ciudad de México. En febrero de 2015 cambió a PROCDMX, S.A. de C.V 
2016). iii. Recientemente se analiza la gentrificación a partir del consumo, desde las ideologías de los diversos agentes en la creación de un rent-gap simbólico (Díaz y Salinas, 2016) y a través de la tematización de la ciudad como estrategia gentrificadora para el incremento del consumo (Olivera, 2017). En este trabajo consideramos la formación de una nueva etapa de gentrificación neoliberal de carácter extendido ante el proyecto inmobiliario de "ciudad compacta" en la Ciudad de México planeado para las próximas dos décadas.

De acuerdo con Neil Smith, cinco elementos definen la gentrificación extendida y se derivan de la interacción entre el Estado, la globalización y el neoliberalismo (Smith, 2002: 441). 1) La transformación del Estado en agente promotor del mercado, cuando se asocia con los privados, lo cual tiende a la realización de desarrollos más caros y simbólicos; 2) La gentrificación se convierte en un fenómeno global y cíclico por la influencia del capital financiero; 3) La transformación de la oposición de grupos anti-gentrificación, paulatinamente sustituidos con acciones represivas y su asimilación política, beneficiados por los cambios; 4) La difusión de la gentrificación fuera de las áreas centrales por condiciones particulares de atracción de inversiones; y 5) La gentrificación a partir de desarrollos inmobiliarios no solo de vivienda, sino comerciales y de servicios.

En la Ciudad de México encontramos estos procesos generales que involucran al Estado, al capital y a la sociedad. En principio, a través de la articulación estratégica entre la asociación público- privada para generar grandes desarrollos inmobiliarios dirigidos hacia diversos submercados, con la adquisición de inmuebles, la derivación de recursos federales, licitaciones (Ley de Asociaciones Público-Privadas) y laxitud en la permisividad para la construcción. Hemos detectado procesos gentrificadores en la Ciudad de México donde estas alianzas público- privadas promueven nuevas centralidades urbanas, todas ellas caracterizadas por el encarecimiento de los precios del suelo y cuyas densas edificaciones e infraestructuras proporcionan servicios profesionales y al consumidor final, vivienda en distintas tipologías para clases medias y altas en Santa Fe, Plaza Carso, Interlomas (Olivera, 2015:102); en la Condesa prodominan la sustitución con comercio minorista y vivienda (Salinas, 2014). El segundo argumento de la gentrificación extendida en la Ciudad de México deriva de la precarización de las clases trabajadoras y la agudización de los desplazamientos de residentes debido a la desindustrialización a partir de la década de 1980, lo que provocó el abandono y deterioro de industrias y viviendas, asimismo la informalización laboral. Estos procesos se asocian con la emigración de más de un millón de habitantes entre 1965 y 2000 de la ciudad interior, del cual 50\% se dirigió hacia el Estado de México, engrosando las periferias metropolitanas (Conapo, 2010). Esto ha dejado grandes espacios centrales detriorados susceptibles de gentrificación.

De acuerdo con Marcuse, pionero en el estudio de desplazamientos, categoriza estos en directos -individual y en cadena- por condiciones económicas y físicas en el barrio; exclusionarios, cuando suponen la desposesión simbólica y material por la elevación del alquiler, de los precios de inmuebles e impuestos; y, por último, bajo la presión de desplazamiento (Marcuse, 2002: 156157). Es entonces la rehabilitación de las viviendas ocupadas por grupos populares el mecanismo que detona el desplazamiento y los sectores de mayor poder adquisitivo elevan la presión (Sequera, 2015). En la Ciudad de México encontramos que los desplazamientos ocurren en esos términos por la desposesión forzada y simbólica (Olivera, 2015:103) derivada directamente de las acciones público- privadas sobre clases populares y medias, articulándose acciones de gobierno, finan- 
cieras e inmobiliarias, con propietarios de esos predios ${ }^{8}$. Para dimensionar la presencia de estos proyectos excluyentes, conviene preguntarse ¿Cómo interactúan estos agentes? ¿Cuáles son las características de las zonas elegidas para los grandes desarrollos? ¿Qué formas de desplazamiento existen? En principio, encontramos tres actores principales en la Ciudad de México: El gobierno local utilizando la "mezcla social" como discurso legitimador de la gentrificación como espacio de reunión de las clases sociales (Lees et al., 2008: 199). El poder corporativo local, amalgamado con el gobierno de la ciudad comparte esta ideología y se beneficia de la asignación de créditos complementarios a sus proyectos. En contraparte, los movimientos de oposición a la gentrificación se organizan y crecen.

Nos centramos en el proyecto urbano corporativo Zodes Corredor Cultural Chapultepec y el Plan Maestro Granadas, los que proponían grandes obras público- privadas de infraestructura, la edificación de usos del suelo "complementarios", incluyendo la ampliación de la oferta comercial. Dentro de esos perímetros se han demolido construcciones, privatizado y fusionado grandes terrenos baldíos para la edificación en altura, apoyada por la reciente normatividad urbana. ${ }^{9} \mathrm{La}$ empresa público- privada Procdmx en conivencia con el gobierno local plantean revertir el decremento demográfico, elevar la calidad de vida y la densificación "promoviendo y consolidando alianzas estratégicas para potencializar el uso del suelo, el aprovechamiento de la infrastructura y el desarrollo del patrimonio urbano"10. La estrategia de Procdmx es la de los desarrolladores urbanos que buscan la mejor localización de sus proyectos para la apropiación de ganancias extraordinarias, mayormente en áreas centrales, en lugares donde arrojen las rentas del suelo más elevadas en el proceso de consumo (Jaramillo, 2009: 177). En ese sentido, Procdmx ha elegido más de 40 intersecciones para el desarrollo de Centros de Transferencia Modal y cinco Zodes en la Ciudad de México, entre otros proyectos.

En esa lógica, los grupos de poder político y económico de la ciudad son agentes que inciden directamente en el mercado del suelo urbano en la Ciudad de México, donde se fija alrededor del $60 \%$ de la inversión extranjera directa a escala nacional (INEGI, 2009). Esto puede explicar el avance de la frontera de la gentrificación, de la ciudad interior a los suburbios metropolitanos, donde las inversiones buscan la rentabilidad más alta y propician espacios de transición con la mezcla de clases en una sociedad polarizada, donde tiende a prevalecer la más opulenta (Olivera, 2013: 119). La renta del suelo urbano adquiere importancia clave porque es un mecanismo de la distribución del excedente social y específicamente de la plusvalía entre inversionistas y propietarios en una fase amenazada por el ritmo de acumulación de los capitales (Jaramillo, 2009), los cuales se dirigen hacia aquellas propiedades con "mayor plusvalía" situadas en atractivas zonas accesibles que ya cuentan con todos los servicios y ambiente de negocios.

El régimen neoliberal en la Ciudad de México la ha transformado en uno de los principales mercados latinoamericanos de oficinas, de negocios, comercio, turismo, servicios profesionales (Olivera, 2014: 163), actividades que generan alrededor del 56\% del PIB urbano (INEGI, 2009). Importantes filiales acuerdan con los gobiernos locales las obras requeridas, entre ellos los grupos

Como lo revelan entrevistas con vecinos de la colonia Torre Blanca y dos antiguos operarios, de empresa reubicada en Naucalpan y del servicio de limpieza (Patricia Olivera y Lorena Rodríguez, julio y octubre 2015; Olivera y Jorge Legorreta, Chamapa. Noviembre 2014).

La Norma 10 del ordenamiento territorial de la Ciudad de México permite el cambio de intensidad de 5 niveles a 22 niveles en los frentes de vialidades primarias en función del tamaño de los predios (Secretaría de Desarrollo Urbano y Vivienda, 2015, disponible en www.seduvi.df.gob.mx)

10 Procdmx, disponible en Internet: http://www.procdmx.mx) 
financieros externos, como Santander, BBVA y HSBC, los que cuentan con los mayores ingresos hipotecarios en el país (Carrillo y Gomís, 2011). Las trasnacionales concesionarias de obras públicas, OHL y Copri, reciben el $99 \%$ de los ingresos derivados del uso de la infraestructura vial de cuota (Samaniego, 2015: 32). Se multiplican los ejemplos de las formas de circulación del capital inmobiliario y la transformación de las ciudades a través de megaproyectos, como ocurre en Londres con el desarrollo del distrito corporativo en South Bank, una de las zonas más deprimidas, 1 la remoción de favelados en Río de Janeiro para la creación de infraestructuras siguiendo una lógica de mercado (Abramo, 2011: 257), en la Ciudad de México, la producción de espacios corporativos y vivienda de lujo sobre antiguos asentamientos dispersos de mineros (Olivera, 2013).

\section{Gestión neoliberal de proyectos inmobiliarios y resistencias en la Ciudad de México}

Durante más de tres décadas las políticas neoliberales generaron desafíos para el gobierno, con la atracción de inversiones privadas como objetivo clave en la reestructuración urbana (Cuenya y Corral, 2011). Se conformó una nueva modalidad de gobernanza, cuyas características principales son: 1) Alianzas entre el sector público y privado; 2) La ejecución y diseño de proyectos especulativos; y 3 ) Fortalecimiento de la economía política del lugar y no del territorio (Harvey, 2001: 373-374). Estas formas de gobernanza neoliberal conllevaron la recomposición del poder, con la integración de estrategias empresariales y planeación estratégica para el desarrollo local, bajo la racionalidad y la fuerza del mercado subsumiendo las problemáticas socio espaciales complejas, tales como la problemática de la vivienda popular, empleo, interlocución con movimientos sociales y el diseño de un proyecto incluyente (Olivera, 2014).

En la Ciudad de México, estas políticas neoliberales tratan de aplicar las estrategias de "ciudad compacta", tecnologías de "Smart Cities" y otros eufemismos a partir del control y transferencia de plusvalía, derivada de las promociones de grandes desarrollos tecnológicos, comerciales, corporativos y de usos mixtos para incrementar el consumo. La lógica de mercado que satura la ciudad del comercio departamental y la verticaliza, además de establecer las condiciones para la acumulación de capital, paralelamente invisibiliza a sectores populares quienes se ven excluidos de su ciudad. Esta política se expresa en el primer objetivo de las Zodes "Orientar el desarrollo urbano hacia una ciudad compacta, dinámica, policéntrica y equitativa, que potencie las vocaciones productivas y que fomente la inversión, para alcanzar un patrón de ocupación eficiente que induzca la redistribución de la población a zonas que combinen los diversos usos del suelo, mejore la infraestructura pública, aproxime el empleo y los hogares a las redes de transporte público y propicie la equidad territorial" (Declaratoria de concesión de obras del proyecto Chapultepec, Gaceta Oficial del Distrito Federal, el 24 de octubre de 2013). Este ideario de las empresas inmobiliarias responde al interés en la fijación de grandes capitales en la ciudad después de las crisis de 2001 y 2008. Los grupos financieros se fusionaron con intereses industriales y del comercio, con los inmobiliarios y con la participación de actores políticos que se mueven en las fronteras de esas actividades (Basave y Gutiérrez, 2013). La Ciudad de México se comporta como la principal sede

Apud. London Tenants Federation et al., An Anti-Gentrification Handbook. 2014. Disponible en Internet: https://southwarknotes.files.wordpress. com/2014/06/staying-put-web-version-low.pdf 
del creciente mercado inter-empresarial, los principales clientes de las empresas industriales y de servicios en esta ciudad son otras empresas, incluidas las del sector público.

\section{Colonia Juárez, clave del desarrollo potencial para el proyecto Corredor Cultural Chapultepec}

La colonia Juárez forma parte del primer ensanche de inicios de siglo XX en el poniente de la Ciudad de México y, junto con las colonias aledañas Roma Norte, Roma Sur, Condesa, Hipódromo e Hipódromo Condesa se desarrolló para la clase alta. Hacia la segunda década del siglo XX, la crisis económica y la inestabilidad política posrevolucionaria generaron la salida de la elite, muchas casonas y palacetes fueron abandonados y la población que fundó la colonia Juárez, en su mayoría, se mudó hacia otras nuevas colonias residenciales. En 1942 se instituyó el régimen de rentas congeladas en el país y la ausencia de inversión inició el proceso de deterioro y abandono que caracterizó más tarde a diversos barrios y colonias, como se ha documentado en el Centro Histórico (Suárez, 2010: 44) y en la Condesa (Salinas, 2013 y 2014). El abandono y deterioro posteriores a los sismos de 1985 propiciaron la ocupación de población de menores ingresos, mezclada con clases medias, artistas e intelectuales que apreciaban las cualidades arquitectónicas y la centralidad de estas colonias.

Los proyectos neoliberales de la década de 2000 intentaron aprovechar el desarrollo comercial de las colonias Roma, Condesa, Hipódromo (Salinas, 2013) hacia la colonia Juárez, por su "vocación comercial complementaria". La agencia Procdmx se interesó por su posición céntrica enmarcada en las históricas avenidas Paseo de La Reforma, su convergencia con la Avenida Insurgentes (atraviesa el centro de la colonia), la Avenida Chapultepec y la calle Bucareli; asimismo su contigüidad al Centro Histórico, ver Figura $N^{\circ} 1$. De acuerdo con el proyecto inmobiliario denominado Zodes Corredor Cultural Chapultepec-Zona Rosa (CCCh), la Avenida Chapultepec se convertiría en un espacio privado mediante la oferta de comercios y sitios de vida nocturna, junto con un área jardinada en un segundo piso, además de vivienda en altura. En ese sentido, se quería constituir a la Avenida Chapultepec en un corredor de alta renta potencial por su localización y accesibilidad este- oeste dentro de la ciudad. Lo anterior debido a que se halla deteriorada considerablemente, por los sismos de 1985, a pesar de que hubo una sustitución de edificios colapsados y actualmente presenta una mezcla de vivienda y pequeño comercio a escala barrial. En 2014, Procdmx presentó el proyecto concesionado por 40 años a un grupo financiero- inmobiliario por el entonces titular de la Secretaría de Desarrollo Urbano y Vivienda (Seduvi), Salomón Newman. El director de Procdmx, Simón Levy, en asociación con el consorcio Invex propuso el "uso, aprovechamiento y explotación" de la Avenida Chapultepec. Aunado a esto, en el extremo poniente se desarrollaría otro proyecto complementario, el Centro de transferencia multimodal (CETRAM), en el cruce con Insurgentes, en el cual ya hay una torre de usos mixtos, vivienda, hotel, centro comercial y terraza, edificada en 2015 y con alto índice de desocupación.

La estrategia adoptada consistió, de acuerdo con el citado funcionario Levy, en que "Invex invertiría en el CCCh $\$ 1.757$ millones de pesos" (alrededor de 64 millones de dólares estadounidenses de 2016). La Secretaría de Desarrollo Urbano y Vivienda (Seduvi) quería legitimar el proyecto afirmando que "integra la participación ciudadana en la gobernanza"... "genera empleos, el gobierno se transforma de recaudador a generador de riqueza pública, para que los beneficios 
se lleven a más personas"..$^{2}$ Por su parte, el gobierno de la delegación correspondiente aplicaría \$224 millones de pesos (12,1 millones de dólares) en algunas obras de infraestructura, para facilitar a Invex la inversión, aun cuando inicialmente el director de Seduvi decía que "el gobierno no invertiría un solo peso en el CCCh" (INE, 2015). Con esas obras, el proyecto pretendía modificar la intensidad de uso en la colonia Juárez con edificaciones de hasta 40 niveles en la Avenida Insurgentes, o de 50 niveles en Paseo de La Reforma. Sin embargo, el proyecto no se presentó a consulta pública, los vecinos obtuvieron el documento del proyecto un año más tarde, en febrero de 2015 a través de una solicitud de información oficial. La que indicaba, se busca "un uso flexible que permita la inclusión de comercios en la planta baja, oficinas, habitación y hoteles en los niveles siguientes". Se contemplaba la construcción de una "rambla comercial" con pequeños locales, andadores, terrazas, áreas comerciales, zonas de actividades culturales, y la construcción de jardines y paseos peatonales en un nivel superior al de la calle (Calidad de Vida, 2014).13 Cabe destacar que los funcionarios de Procdmx y de la propia Secretaría de Desarrollo Urbano y Vivienda de la Ciudad de México (SEDUVI) ocultaron la mayor parte de la información generada acerca del proyecto, el cual incluye "un polígono de 116.000 m²; cuya construcción comprenderá hasta $79.300 \mathrm{~m} 2$ y hasta $36.700 \mathrm{~m}^{2}$ de estacionamiento subterráneo" (Gaceta Oficial del Distrito Federal, 19 mayo 2014). El proyecto se basó en "el uso, aprovechamiento y explotación del área ubicada sobre y en el subterráneo de un bien público", respaldándose en las Leyes del Régimen Patrimonial y del Servicio Público, que permiten promover la participación, colaboración y coinversión de los sectores social y privado con el gobierno de la ciudad para el desarrollo de proyectos" (Calidad de Vida, 2014). La concesión de este espacio público proponía "usar, aprovechar, explotar, administrar, diseñar, acondicionar, construir, conservar y mantener una calle completa con vocación cultural que incluya espacio público, equipamiento, vialidad, estacionamientos... y otros servicios complementarios para generar "conectividad y accesibilidad" y "que aumente la calidad en espacio y de vida de la ciudad". Esta declaratoria era controversial porque abría los usos privados en un bien público, lo cual fue cuestionado por parte de los vecinos ante las instancias gubernamentales con las cuales trataron de dialogar.

\section{Gentrificación y desalojos. Desplazamiento por el proyecto neoliberal Corredor Cultural Chapultepec}

Esta iniciativa público- privada para la revalorización de la colonia Juárez, la ha "convertido en un espacio en disputa de la Ciudad de México. Se han presentado diversos agentes inmobiliarios, quienes intentan apropiarse por todos los medios de predios y edificaciones para promover desarrollos habitacionales, nuevos espacios del comercio al menudeo, tiendas de artículos de lujo, escuelas privadas, restaurantes de mayor distinción" (Sergio, residente, entrevista 2015). La resistencia al proyecto Zodes Corredor Cultural Chapultepec- Zona Rosa surgió en la colonia Juárez, ante la presión que padecen residentes, propietarios, arrendatarios de vivienda, posesionarios de bienes intestados y pequeños comerciantes, por parte de los agentes inmobiliarios quienes comenzaron a apropiarse predios y edificaciones con escaso mantenimiento y con grados de deterioro visible. Estos agentes pretenden su demolición y la edificación de vivienda en altura o su remodelación y ocupación con nuevos usos comerciales y residenciales. Los vecinos de la clonia Juárez señalan

\footnotetext{
Debate público organizado por el Instituto Nacional Electoral, 3 de diciembre de 2015, previo a la Consulta Ciudadana acerca del proyecto Corredor Cultural Chapultepec (INE, 2015).

13 De acuerdo con el Censo de población y vivienda de 2010, la población total de la colonia Juárez era de 10.184 habitantes, repartidos en 99 manzanas
} 
que desde hace cuatro años se han presentado desplazamientos directos de residentes y comerciantes, "agentes inmobiliarios presionan para adquirir construcciones, para derrumbarlas y edificar viviendas en altura, se presenta un blanqueamiento, es decir, edificaciones con usos populares se transforman en espacios exclusivos, excluyentes" (Sergio, residente, entrevista en 2015).

Cabe destacar que la presión inmobiliaria que refieren los vecinos se inició con las obras en la Avenida Paseo de La Reforma, después de la crisis de 2008, cuando se relocalizaron o llegaron corporativos financieros y de servicios para los negocios. En las intersecciones de las Avenidas Insurgentes y Paseo de La Reforma se están desarrollando usos mixtos y por primera vez vivienda de lujo desde que desaparecieron las mansiones de la élite porfiriana a principios del siglo $X X^{14}$. Este proceso, entre 1992 y 2013 significó la edificación de alrededor de ocho millones de metros cuadrados de espacios para oficinas en la Ciudad de México, de las cuales el $47,9 \%$ se concentraron en Paseo de La Reforma, Insurgentes, Santa Fe y "Nuevo Polanco" (Olivera 2015: 96). Esa dinámica inmobiliaria en Paseo de la Reforma contribuyó a incrementar los precios del suelo en la colonia Juárez. Inversionistas inmobiliarios presionan a los propietarios y posesionarios para desplazarlos. Los vecinos de la colonia Juárez se organizaron para hacer frente a los procesos de desalojo por gentrificación que se están gestando bajo esta lógica empresarial del gobierno de la Ciudad de México.

De acuerdo con los vecinos entrevistados hay tres variantes de las formas directas de desplazamiento, una derivada del incremento de los alquileres por parte de los propietarios y la segunda a partir de los nuevos agentes, quienes proceden a la demolición y aplicación de nuevas inversiones. Asimismo, se presenta un desplazamiento simbólico muy concreto al convertirse en un espacio de exclusión social. La organización de los vecinos ha logrado frenar algunas acciones de esos agentes, lo que creó una conciencia y unidad entre sus miembros "El dueño no quería darnos contrato [de arrendamiento], querían sacarnos, nos pidieron a todos los inquilinos que desocupáramos el edificio en un plazo hasta abril [de 2016]; pero por la organización que tenemos aquí se hizo un nuevo contrato" (María, residente, entrevista 2016). "La renta se disparó hace 4 años, todos los vecinos se pusieron de acuerdo para la conciliación y entonces bajaron un $40 \%$, solo un local está en pleito legal, los demás si se unieron" (Alfredo, comerciante, 2015). "El edificio donde vivo está semi-abandonado, varias familias se fueron por el encarecimiento de servicios, algunos viven en la colonia con amigos o se fueron, no sé dónde" (Darío, residente, 2015).

El desalojo directo tiene gran peso en la experiencia vecinal: "Desalojan, los vecinos y comerciantes se enteran, seguido tratan de desalojar; pero la gente es solidaria y se organiza" (María, comerciante, 2016). A partir de lo cual se han gestado lazos de reciprocidad con «los otros» basado en su derecho de arraigo "Hay videos sobre el desalojo del edificio donde vivían los indígenas otomíes, sacaron sus cosas a la calle, levantaron un campamento en la calle, allí viven ahora, los vecinos se solidarizaron argumentando que habían llegado hacía más de 15 años" (Sergio, residente, 2015)15. "Quieren desalojarnos porque tenemos muchos años aquí, y no quieren que

\footnotetext{
14 Paseo de la Reforma es una de las principales avenidas de la ciudad y el corredor de negocios más antiguo, sede de la elite porfirista (18761910). La actual política neoliberal impulsa grandes megaproyectos corporativos, ubicados entre el parque urbano más antiguo de la ciudad, La Alameda, en el Centro Histórico, hasta el distrito corporativo Santa Fe en el poniente, conformando un corredor de 17 km con usos financiero, hotelero y turístico, un espacio público fundamental en la vida política urbana (Pradilla, 2010; Olivera, 2013).

15 "Desalojan a Otomíes en la Juárez", Diario de México, 27 de noviembre de 2014. Disponible en Internet: http://www.diariodemexico.com.mx/ desalojan-otomies-en-la-juarez/
} 
tengamos derechos por antigüedad" (María, residente, 2016). Identificaron el conflicto y las consecuencias en el barrio "La gentrificación perjudica a la colonia, se vuelve más cara, mi negocio se va para abajo y tendría que poner un negocio de lujo y vender caro" (Alfredo, comerciante, 2016). "Al subir la renta se fueron los de las tortas y llegó un restaurante gourmet" (María, comerciante, 2016). "Con la construcción del Reforma $222^{16}$ sacaron a mucha gente de la colonia, pero la población [flotante] ha crecido bastante, el abastecimiento de agua ha disminuido, sube la luz y el teléfono" (María, residente, 2016). Las entrevistas también muestran que los vecinos identifican a los agentes gentrificadores y sus acciones "La inmobiliaria Abilia me pidió el local, cobra 9.000 pesos y no ofrece mantenimiento; renta otros locales, una estética, farmacia y también alquilan departamentos. Ellos estuvieron detrás del Corredor, pero los frenaron las protestas de vecinos" (María, comerciante, 2016). Actualmente, las edificaciones desalojadas se han gentrificado y predominan los conjuntos habitacionales nuevos y remodelados para sectores medios- altos, mezclados en planta bajo con cafés y restaurantes. Se alternan con oficinas y escuelas privadas de grados medio y superior; en tanto que las mansiones remodeladas albergan comercio minorista y restaurantes de lujo.

Frente a una postura crítica de la subalternidad, los vecinos realizan acciones colectivas, han creado un Observatorio Ciudadano, con medios propios y algunos apoyos, para documentar los desplazamientos y abusos de agentes inmobiliarios. De acuerdo con sus levantamientos, la Plataforma Vecinal 06600 de la colonia Juárez ha detectado que cerca del 10\% de la población de la colonia ha sido desalojada, ver Figura $N^{\circ} 1$. La exigencia de sus derechos ciudadanos, la disponibilidad de trabajo colectivo y cohesionado ante la amenaza del proceso de despojo han fortalecido la organización y la necesidad de plantearse estrategias viables de defensa, conformando una lucha anti-gentrificación muy activa, con propuestas propias y articuladas con otras organizaciones. Todos ellos elementos estructuradores de una resistencia social en permanente acción (Modonesi, 2014). A través de las frecuentes deliberaciones entre residentes, en su mayoría profesionistas y comerciantes, con autoridades de la Ciudad de México sobre el proyecto CCCh, se manifestaron los argumentos sustantivos para la defensa de su arraigo. Destacaron anomalías del proyecto, entre ellas, que las obras se concesionaron de manera irregular, antes de la aprobación pública del proyecto, no hubo consulta ciudadana y se trató de imponer la conversión del espacio público en privado.

La Plataforma Vecinal 06600 fortalece y difunde la conjunción de intereses y demandas de otros vecinos organizados de las colonias Roma y Condesa, quienes constituyeron un frente amplio y representativo que ha dialogado con todos los grupos locales, desde los representantes ciudadanos (algunos de ellos militantes de partidos o coptados), funcionarios de Procdmx, la Seduvi, la Secretaría particular del gobierno de la ciudad e incluso con miembros de partidos políticos. Se han presentado en diversos foros de discusión, ${ }^{17}$ para expresar y defender sus demandas, su independencia política, su postura anti-gentrificación e interés propositivo en el arraigo social, aunado a la memoria histórica y el respeto del espacio público en el barrio y en la Ciudad de México. Se adhirieron a la Plataforma Mexicana por el Derecho a la Ciudad y en Defensa del

\footnotetext{
Desarrollo vertical de usos mixtos en Reforma, del grupo Dahnos; su director es exfuncionario público.

Foro de Diálogo sobre gentrificación y por el Derecho a la ciudad, 16 abril 2015, Centro Cultural Universitario Tlatelolco, Ciudad de México, en el $4^{\circ}$ Seminario Internacional Contested Cities. Disponible en Internet: http://contested-cities.net/CCmexico/2015/03/31/gentrificacion-derecho-a-la-ciudad/ Dia Mundial del Habitat, abril 2015; Coloquio Perspectivas de la gentrificación en América Latina, UNAM 1-4 abril, 2014.
} 
Territorio en abril de 2015, un frente que convoca a numerosas organizaciones del movimiento urbano popular, contra las Zodes y otros proyectos excluyentes.

Figura $\mathrm{N}^{\circ} 1$

Desplazamientos de vivienda en la colonia Juárez, Ciudad de México

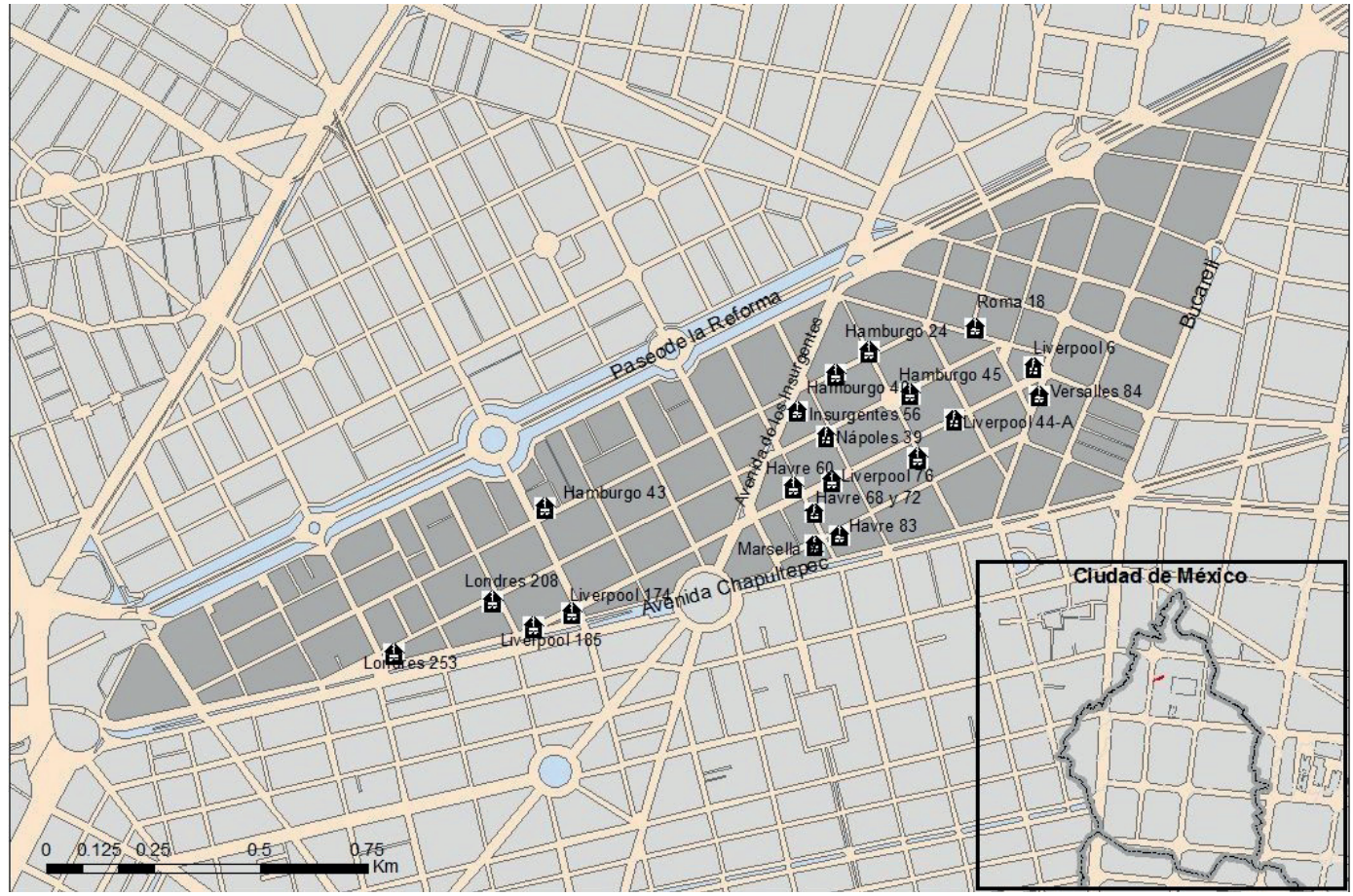

Fuente: 06600 Plataforma Vecinal de la Colonia Juárez, 2015.

Nota: La dirección hace referencia a los inmuebles en donde se han presentado desplazamientos de población.

Durante dos años de lucha han impedido dos consultas ciudadanas espurias, y su participación en la Consulta Ciudadana el 6 de diciembre de 2015, cuya entidad responsable fue el Instituto Nacional Electoral, les otorgó una victoria. La Plataforma Vecinal presentó dos argumentos centrales por el NO a la Zodes Corredor Chapultepec. En el debate organizado por el INE el 3 de diciembre de 2015:

"Los vecinos decimos 'Así no', es decir, no estamos en contra de mejorar la Avenida Chapultepec, sino planteamos otras formas de intervenir, a nivel de piso, para que el peatón, ciclista, discapacitado, comerciante, haga uso del espacio público. En esta obra de gran magnitud hubo una ausencia de consulta a los ciudadanos acerca del diseño, uso y destino final del espacio público por excelencia que es la calle. No se consultó a las principales colonias afectadas y en una segunda fase al resto de la ciudad. Esta obra sienta un precedente de la ciudad que queremos, la voz de los ciudadanos es imprescindible para decidir 
qué se pretende construir porque afecta a todos los ciudadanos" (Tania, residente y representante de la Consulta Ciudadana del 6 de diciembre de 2015).

"El corredor comercial significaría la privatización de la calle, del Acueducto Chapultepec, que es patrimonio nacional. El proyecto es un negocio comercial y no cultural. La Avenida Chapultepec es zona de riesgo sísmico; de los ingresos que genere este negocio, el gobierno recibirá solo el $5 \%$, pero se elevarían los impuestos; el corredor beneficiaría a las empresas amigas de los que están en el poder, se viola el Artículo 47 del Reglamento de Servidores Públicos [sobre Transparencia en las acciones de gobierno], el director de Procdmx no ha respondido en manos de quien esta este corredor" (Margarita Isabel, residente y representante de la Consulta Ciudadana).

Por otra parte, representantes por el SI, justificaron el proyecto "para atraer inversión externa, resolver caos vial, ampliar espacio público de calidad, caminar con seguridad". "No genera deuda pública, sino empleos, desarrollo, capta riqueza. Se involucra a los ciudadanos y a expertos para redefinir y dar nuevas formas a los proyectos de barrio. A quienes quieran invertir se les entregarían certificados de participación social, esta obra generará plusvalía social" (Simón Levy, director Procdmex, INE, 3 diciembre 2015).

La consulta ciudadana se realizó el 6 de diciembre de 2015, obtuvo el triunfo el NO. Los vecinos de la Plataforma Juárez siguen en guardia, la presión no ha cesado. Las condiciones que han facilitado los desalojos continúan, hay edificios en riesgo de colapso, abandono e irregularidad en la tenencia de los inmuebles, estratos sociales de bajos ingresos, indígenas mazahuas y otomíes y estratos medios que alquilan (Pérez, 2014).

\section{Plaza Carso y el "Plan Maestro" Granadas. Reciclamiento, crisis y expulsión}

Ambos desarrollos son representativos del auge del urbanismo neoliberal de la Ciudad de México en el marco de las asociaciones público- privadas. La estrategia de estas asociaciones se basa en dos premisas principales: la orientación de este mercado al consumo de segmentos sociales de ingresos medios- altos dispuestos a pagar la oferta de vivienda: residencial y residencial plus; y los desarrollos mixtos: corporativos, culturales, comercio departamental, acompañados de una amplia diversidad de servicios. La segunda premisa surge de la conjunción de intereses de los gobiernos neoliberales, los nuevos desarrolladores, empresas constructoras, bancos, aseguradoras e intermediarias financieras para apropiarse de las elevadas rentas del suelo.

La estratégica localización de Plaza Carso y desarrollos en Granadas, siguió el principio básico de la valorización del suelo por las ventajas adicionales. Por una parte, su adyacencia a Polanco, un barrio de la burguesía comercial establecida desde la década de 1930 por inmigrantes y nacionales, libaneses, estadounidenses, españoles y más tarde sudamericanos, entre otras nacionalidades. Actualmente, es el barrio más lujoso de la ciudad, consolidado con usos residenciales, profesionales y comercio minorista de lujo. Aquí se ubica la calle comercial más cara del país, Masaryk, en el corazón de Polanco. Cuenta con la mejor calidad de infraestructura urbana, los ingresos per cápita más elevados y los sitios de residencia y consumo más exclusivos. La organi- 
zación de los residentes y empresarios de Polanco se distingue por el control que históricamente han ejercido sobre el gobierno delegacional de Miguel Hidalgo, dirigido tradicionalmente por el Partido Acción Nacional -el más conservador. Han influído decisivamente a favor, o en contra, en los cambios de los programas urbanos en materia de usos, vialidades, densificación, entre otros, para mantener el alto nivel del barrio.

Aunado a lo anterior, la ubicación de Plaza Carso y los desarrollos de Granadas, se deben a los extensos predios vacíos de plantas fordistas relocalizadas desde la década de 1990, colindantes con un área muy deteriorada al norte. Grandes desarrolladores como Danhos, Grupo Abilia, Inmuebles Carso adquirieron los antiguos predios industriales de General Motors, Chrysler, Colgate-Palmolive, Euzkadi y la planta Tire, para convertirlos en grandes centros comerciales, como Antara, la nueva Embajada de los Estados Unidos de América y el corporativo Carso. A partir de entonces, grupo Carso, liderado por el Ing. Slim, ha puesto de manifiesto la importancia de la valorización inmobiliaria como uno de sus intereses principales de inversión del corporativo (Olivera, 2013). También se aprovechó la zonificación establecida en el Programa Delegacional de Miguel Hidalgo en 1997, la que definía una amplia área al norte de este barrio y de la delegación, con polígonos clasificados como Zonas de Potencial de Reciclamiento y Áreas con Potencial de Desarrollo. Esta zonificación de uso intensivo también incluye las colonias del norte y este de Plaza Carso, cuyos predios están ocupados con vivienda de clases populares, talleres e industrias, con un alto proceso de abandono (Olivera, 2013: 105). La convergencia de condiciones de proximidad al mercado de alto ingreso en Polanco y, por otro lado, el abandono, las grandes dimensiones de los predios y población trabajadora carente de tenencia legal de la vivienda, constituyeron condiciones inmejorables para la apropiación de elevadas rentas, lo que hace muy estratégica a esta zona.

El Bando 2 fue el detonante para la edificación intensiva, surgieron desarrolladores inmobiliarios muy interesados en estos grandes predios rezonificados y de alta construibilidad. En 2003 la Inmobiliaria Carso gestionó la adquisición del predio industrial de la planta estadounidense Tire, en la colonia Granadas. Por otro lado, se fusionaron otros predios para elevar la intensidad de edificación de 5 niveles, según la zonificación de 1997, a 22 niveles en 2005. Ante el incremento de la demanda de suelo por los grandes desarrolladores para su edificación vertical en negociación con la Secretaría de Desarrollo Urbano y Vivienda (Seduvi) de la Ciudad de México, se otorgaron momentáneamente permisos para la elevación a 50 niveles, a reserva de la realización de estudios de impacto urbano, lo que resultó en la aplicación de medidas mínimas. Por ello se desarrollaron los megaproyectos Plaza Carso, Antara y Polárea. Este último, del grupo Lar, en asociación con el famoso despacho de arquitectos Legorreta desarrolló en 2009 el Plan Maestro de Polárea, un lujoso desarrollo de uso mixto comprendido entre vialidades de gran circulación, Avenida Río San Joaquín y Ejército Nacional. Ver Figura 2. Sin embargo, en 2012, Carso compró el 70\% de este predio, debido a la insatisfacción de los adquirentes de la pre-venta por incumplimiento de obras. Actualmente, se construye un total de 14 torres, con departamentos de 57 a 165 metros cuadrados de superficie y precios entre 95.000 a 350.000 dólares, con infraestructuras para la recreación y el consumo al interior de las torres. Este formato de uso mixto se adoptó por los desarrolladores como estrategia ante la densificación, saturación y caos vial que comenzó a generarse desde 2008 en Granadas y colonias aledañas por la contigüidad de las construcciones, en esta zona de alta densidad vehicular y poblacional de alto ingreso en la Ciudad de México. 
En 2013, Seduvi financió el Plan Maestro de Granadas para ordenar la urbanización, disminuir la especulación del suelo, la elevación de los precios, el caos vial y de servicios en la zona. ${ }^{18} \mathrm{El}$ Plan Maestro pretendía combinar desarrollos de vivienda en altura, torres de oficinas, extensas áreas verdes, jardines lineales sobre vías de ferrocarril, plazas comerciales y vivienda de densidad media y baja, así como usos culturales y mercados. En su interior se ubicaban los predios de las plantas industriales más grandes de la zona, con ello se pensaba abrir un nuevo espacio para el reciclamiento urbano. Sin embargo, se gestó un crecimiento incontrolado de edificaciones que causó la saturación vial y el colapso de todos los servicios e infraestructura urbana. Ante lo cual, en agosto de 2013 la Seduvi suspendió todas las licencias de construcción y en abril de 2015, expidió el acuerdo Sistema de Actuación por Cooperación (SAC) Granadas 19 "para el mejoramiento y consolidación sustentable del polígono en 12 colonias, donde se encuentran los mega-desarrollos citados"20.

Los colonos indican que se les ha negado información sobre el Plan Maestro y sobre el SAC y han organizado diversas acciones para enfrentar esta situación crítica. Refieren que el SAC consiste en el acuerdo directo entre desarrolladores y autoridades delegacionales y de Seduvi para el otorgamiento de permisos, licencias y autorizaciones a inversionistas, quienes aportan a cambio, recursos para obras de mitigación, que depositan en un fideicomiso privado, sin rendición de cuentas, ni control fiscal. ${ }^{21}$ En comparesencia del titular de Seduvi ante la Asamblea Legislativa de Representantes, ${ }^{22}$ este señaló que el SAC Granada es una "estrategia de reordenamiento, que considera la consolidación de la vocación del suelo, o la reestructuración, revitalización, regeneración, a partir de lo cual se desprende una cartera de proyectos, los cuales se consensan con los integrantes de la Mesa de seguimiento permanente para ver el orden de ejecución y se cuantifica el costo de los proyectos, se fija para cada desarrollo cuanto debe contribuir al SAC de acuerdo con la estrategia del plan"..."el beneficio es comprobable, si los inversionistas no se adhieren deben apegarse estrictamente a ley de desarrollo urbano".

En la misma comparescencia, diputados del PAN y Morena coincidieron en rechazar “la discrecionalidad para relocalizar usos, destinos y potencialidades, relotificar independientemente de los planes" ... lo que constituye una "violación y evasión de las normas y técnicas en general, las cuales pasan por la aprobación de Seduvi sin consulta pública, sin participación ciudadana". Los vecinos señalan que "es básicamente un fideicomiso privado inauditable que recaudará recursos de las constructoras para realizar obras de mitigación e infraestructura. Se estima que maneja más de 3.600 millones de pesos (195 millones de dólares estadounidenses, febrero 2016). No será un ente obligado en materia de transparencia, ni tendrá participación ciudadana en su comité técnico" (Gustavo García, residente, integrante de la Asociación de Condóminos de Granadas- Anáhuac, febrero 2016). Las asociaciones de vecinos ganaron en enero de 2016 el amparo colectivo interpuesto por 20 colonias, solicitando la suspensión de megaproyectos de desarrollo urbano en la zona conocida como «Nuevo Polanco», asimismo la suspensión provisional del SAC ${ }^{23}$.

\footnotetext{
En 2010 en la colonia Granada, el m2 de terreno costaba 20.000 pesos y en 2012, 45.000 pesos el m2.

Diario Oficial del Gobierno del Distrito Federal, 17 abril 2015.

Comprenden las colonias Granada, Ampliación Granada, Popo, Ampliación Popo, Anáhuac I Sección, Modelo Pensil, Cuauhtémoc Pensil, Dos Lagos, Irrigación, Los Manzanos, Mariano Escobedo y Verónica Anzures, en la Delegación Miguel Hidalgo.

Entrevistas de Patricia Olivera con vecinos de Granadas, febrero 2016.

2 Comparescencia del secretario de Desarrollo Urbano de la Ciudad de México en el Máximo órgano legislativo de la Ciudad de México (18 de septiembre de 2016)

23 Ver publicación periódica de la asociación de vecinos. Disponible en Internet: http://www.espejored.com
} 
Figura $\mathrm{N}^{\circ} 2$

Desarrollos inmobiliarios de vivienda, corporativos e industrias en Polígono Granadas (SAC)

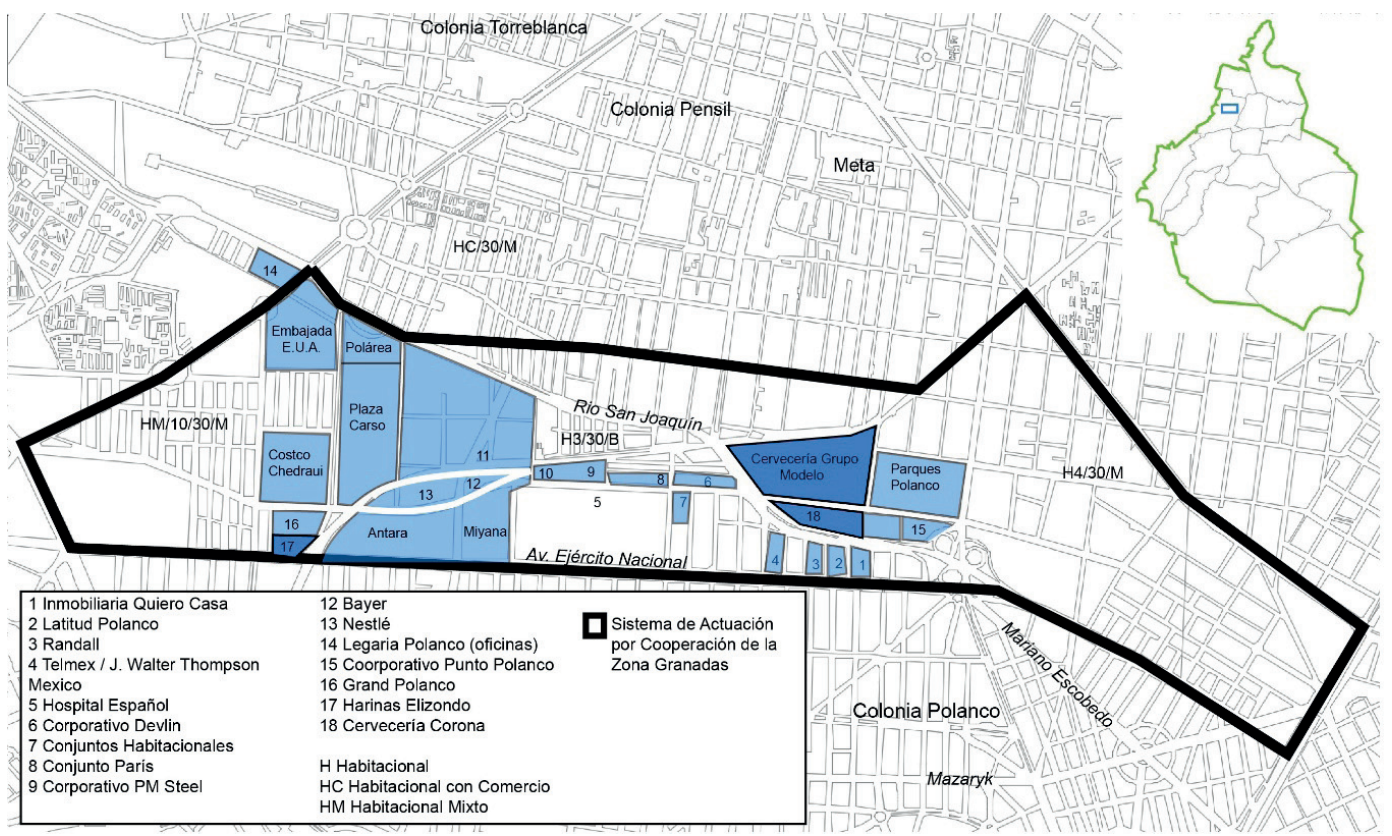

Fuente: Patricia Olivera, con base en trabajo en campo 2016.

Plaza Carso se inició en 2008 y concluyó en 2010, es un espacio corporativo de uso mixto, emblemático del poder económico prohijado en el neoliberalismo, combina la producción de bienes y servicios procedentes de sus empresas de todos los sectores, con un elevado consumo. Plaza Carso se integra con edificios de vivienda, oficinas usos mixtos, hotel, teatro y museos y un centro comercial. Los desarrollos inmobiliarios de conjuntos habitacionales lujosos aledaños a la Plaza Carso, Polárea, Miyana, Dos Patios y otros, se han sumado a la presión del suelo que atrae pequeños y medianos capitales que están amenazando a 36 colonias populares con la estrategia del gobierno local para favorecer el reciclamiento y redesarrollo con usos rentables, a partir del cambio de la zonificación. Figura $N^{\circ} 3$. En los programas urbanos se integraron usos complementarios, rentables todos ellos, y se elevaron las densidades propuestas, entre las más altas de la Ciudad de México, lo que hace insuficiente la infraestructura existente.

Agentes inmobiliarios en la zona pretenden aprovecharse de las condiciones de elevada inseguridad en la tenencia de la vivienda y la falta de servicios públicos. Residentes originarios señalan acciones de desplazamiento en el norte de Polanco. Entre las colonias amenazadas están Torre Blanca y Pensil, constituidas entre las décadas de 1930 y 1980, dentro de la zona de pequeña industria, mezclada con vivienda popular y talleres, la cual forma parte de la extensa zona industrial ubicada en el norponiente de la Ciudad de México, la que se prolongaba hacia Naucalpan, en el estado de México. La relación entre los proyectos inmobiliarios de gran impacto y la gentrificación extendida está condicionada a del avala continuación de las obras y las acciones 
Figura $\mathrm{N}^{\circ} 3$

Reciclamiento de industrias por desarrollos habitacionales para clases medias altas, al frente equipamiento en construcción. Este de Plaza Carso, Colonia Granadas, norte de Polanco,

\section{Ciudad de México}

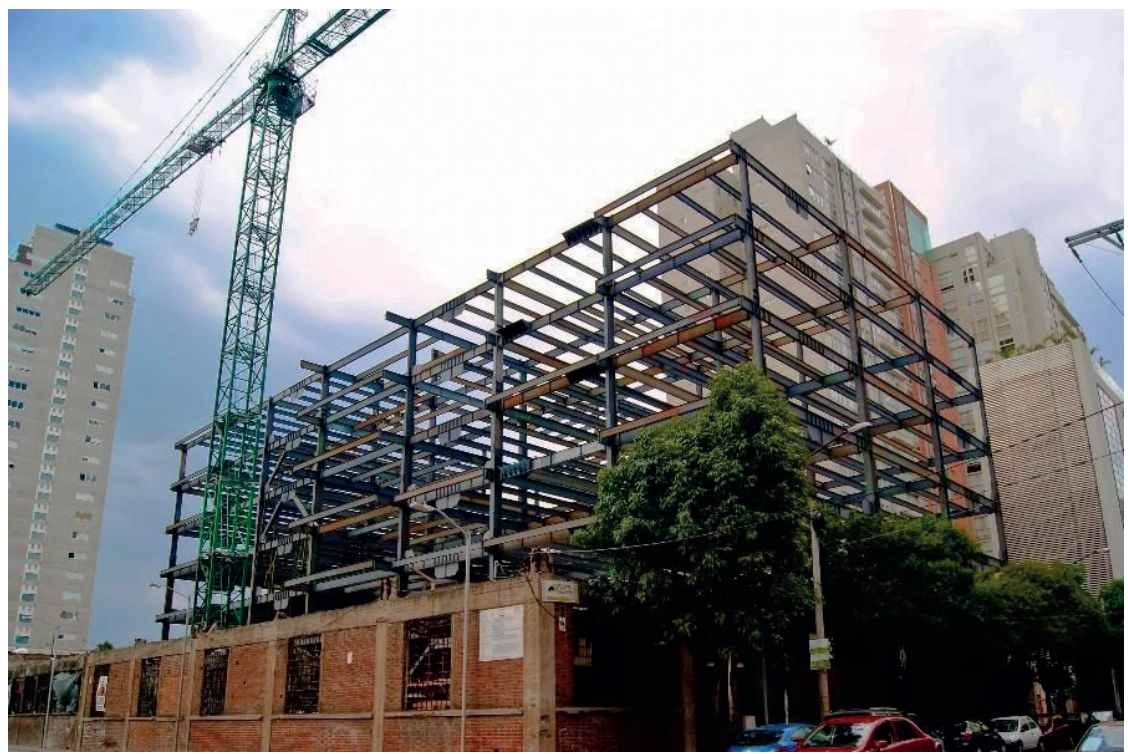

Foto: Ariadna Martínez, septiembre 2015.

del gobierno local. De acuerdo con los testimonios de residentes, esto ha generado presiones de inmobiliarias e incertidumbre.

\section{Procesos de desplazamiento en la zona norte de Polanco}

El desplazamiento social por la gentrificación no aparece en las políticas públicas, en primer lugar, aducen la escasez de presupuesto social, entonces pasa a su normalización. En segundo término, conciben la gentrificación acelerada como un beneficio, un resultado positivo de la renovación urbana. No se reconoce que este proceso responde a una condición de clase, la expulsión ha recaído principalmente sobre los segmentos pobres de la clase trabajadora como lo discuten Newman \& Wyly $(2005,45)$. La presión de inmobiliarias pequeñas y grandes en la zona norte de Polanco, específicamente en las colonias Torre Blanca y Pensil, se encuentra en una fase inicial de la gentrificación, relativa a la adquisición de algunos predios degradados. Esta fase ya ocurrió en las colonias Granadas y adyacentes, donde demolieron las plantas industriales de Chrysler, General Motors y Euzkadi, entre otras. En la colonia Torre Blanca, las prácticas de las inmobiliarias coinciden con aquellas de la colonia Juárez, en el sentido que detectan las viviendas y predios con procesos irregulares de tenencia, sea por abandono de los dueños o por bienes intestados y presionan a los inquilinos para desalojarlos presentándose como propietarios. Los vecinos del norte de Polanco señalan que los impuestos se dispararon "Los pagos por predial y agua se fueron a las nubes, pero esta situación no se puede arreglar, porque no cuento con escrituras" (Luis, residente. Entrevista, 2016), o se trata de propiedades intestadas. La situación precaria de muchas familias afectadas les impide regularizar su situación a través de juicios de usucapión a los cuales 
tendrían derecho por su permanencia de buena fe en la vivienda en un lapso mayor de 10 años, en la mayoría de las ocasiones no pagan el alquiler debido a la ausencia de los propietarios. Sin embargo, aquellos que adeudan el pago de impuestos por los servicios urbanos derivado de su condición de escasez, los deja en una situación vulnerable ante las autoridades y a merced de las inmobiliarias. Esta situación es muy frecuente en las colonias aledañas y es un problema añejo que no ha sido estudiado.

En estas colonias del norte de la delegación Miguel Hidalgo, como Torre Blanca y Pensil, las acciones para la apropiación de ciertos predios por parte de las inmobiliarias han sido incluso violentas, a través de la práctica bulldozer en la madrugada o cuando los residentes se encuentran en horarios de trabajo. Otra práctica frecuente de estos agentes es hacer uso de recursos para el soborno y facilitar los desalojos. Los testimonios indican que diversas instancias gubernamentales han jugado un papel explícito en estas acciones de apoyo a los desalojos directos, acompañando con información catastral y documentación alterada de la propiedad. "En [la calle] Lago Amatitlán, el predio de $1.800 \mathrm{~m}^{2}$, desde hace 9 años se halla en resguardo vecinal porque la empresa inmobiliaria Amiga Jaspi empezó a construir al lado de la vecindad donde viven 14 familias, después querían sacarlos. Primero ocuparon la fábrica abandonada al lado, la demolieron y afectaron a la vecindad, pues taparon el paso con la intención de demolerla, pero los sacamos. Las familias están resguardando el paso dia y noche para que no vuelvan a cerrarlo". La inmobiliaria "no tenía permisos de demolición, aun así, después construyeron dos torres de 10 pisos, junto con otro terreno. El dueño se murió hace como 30 años y su título de propiedad [el que muestra la inmobiliaria] es de hace tres años. Las autoridades no nos escuchan" (Bertha, residente miembro de la Asociación de Vecinos Anahuac, entrevista julio 2015). Por este tipo de arbitrariedades "hemos hecho denuncias en las oficinas de Ordenamiento Territorial (Procuraduría Ambiental de Ordenamiento del Territorio, PAOT), en el Registro público de la propiedad y no nos escuchan. Hemos realizado cuatro cierres [de la avenida] Legaria, la última vez, la policía bloqueó la zona por seis horas. [En esa ocasión] "se aproximaron autoridades de Enlace Ciudadano para que negociaran vecinos y constructoras, les dijimos hasta que no acrediten la propiedad no les permitiremos pasar, sigue en resguardo vecinal el inmueble" (Berta, residente, 2015).

Las acciones de resistencia de las organizaciones se han constituido por colonias y recientemente agrupadas en un Frente, han ido desde el cierre de vialidades primarias para evitar desalojos, hasta propuestas para destinar predios para usos públicos y servicios educativos y de salud, incluso ofreciendo trabajo voluntario. "Hemos tratado de negociar la expropiación de un predio para la construcción de una clínica, un dispensario y la creación de un centro comunitario, pero la delegación no escucha, no soluciona" (Luis, residente de Torre Blanca, entrevista, 2015).

Integrantes de la Red Anáhuac y organizaciones vecinales de distintas delegaciones, aseguraron que en los dos años anteriores la Secretaría de Desarrollo Urbano y Vivienda otorgó 40 mil licencias de construcción para torres habitacionales o de usos mixtos, que amenazan la integridad de barrios, colonias y pueblos. Las declaraciones del director de Obras de la Delegación reflejaron la racionalidad de mercado que interesa a las inmobiliarias, ya que indicó el interés en densificar, construir vivienda e incrementar el uso comercial y de oficinas en colonias populares, lo que significa la aceleración de los procesos de desplazamiento directo y exclusionario (Ramírez, 2015). El director de dicha dependencia informó que el objetivo es potencializar el desarrollo habitacional sobre el uso de suelo comercial y de oficinas, a fin de garantizar que la localidad pase a ser una 
demarcación "de destino y no de uso." En términos de la teoría del valor, esto privilegia el lucro y no el valor de uso. El funcionario señaló que en promedio se construyen 3 mil 600 nuevas viviendas cada año en esa demarcación, lo cual atrae unos 12 mil nuevos habitantes anualmente. Indicó que ante ello fue necesario corregir los vacíos legales que existen en el Programa de Desarrollo Urbano vigente y clarificar los resquicios que deja la ley, para que el crecimiento habitacional se realice de manera ordenada. El proyecto neoliberal de desarrollo urbano de la Ciudad de México propone la política "Ciudad compacta" para justificar la colocación de grandes inversiones inmobiliarias en las colonias populares como la Anáhuac, Torre Blanca y la Pensil, generando procesos de desplazamiento y exclusión social.

\section{Conclusiones}

Los términos de la Ley de Desarrollo Urbano de la Ciudad de México diseñados por el gobierno y desarrolladores inmobiliarios tratan de imponer modificaciones a los usos de suelo en beneficio de los intereses particulares y pretenden legitimarse a través del control de instancias de participación social, para avalar los proyectos con participación social simulada. La imposición de los proyectos analizados genera exclusión y segregación urbana, desposesión de un bien patrimonial con un carácter fundamentalmente de uso y produce el desplazamiento hacia las periferias de la Ciudad de México, fenómeno que pretende ser silenciado. Para dimensionar la extensión de estos nuevos proyectos en el norte de Polanco se identificaron algunos agentes promotores de los desarrollos corporativos, mixtos y de vivienda y también se encontró una gran diversidad de organizaciones que confrontan este proyecto urbano neoliberal, desde clase medias altas en Granadas a clases populares en Torre Blanca y Pensil, asimismo, se encontró el fortalecimiento de las organizaciones vecinales de Juárez, Roma y Condesa, las cuales se articulan a su vez con otras organizaciones, ONG, académicos.

Estos proyectos buscan alterar las identidades de los barrios con usos y actividades que les son ajenas, en Juárez nos expresaron la multiplicación de bares y antros que generan ruido, inseguridad y basura; en Torre Blanca expresaron que autoridades son indiferentes a propuestas para el tratamiento de la drogadicción entre jóvenes, la falta de centros de salud y el subempleo. En ese sentido, los proyectos neoliberales degradan la calidad de vida en los sitios donde se realizan y también en sus entornos inmediatos, generando procesos de saturación vial, privatización de espacios públicos, presión directa e indirecta contra residentes y comerciantes tradicionales, falta de servicios públicos elementales como parte de la estrategia.

La resistencia en los barrios se multiplica, participan diversas clases sociales con acciones para evitar su desplazamiento, solidarias con asistencia legal a vecinos presionados, con otras organizaciones y manejan una difusión mediática con el fin de ser escuchados. Estas acciones se dirigen de manera cada vez más consciente y articulada para ganar espacios de participación en las decisiones de la política urbana, colocando propuestas ciudadanas para el bienestar social, no sólo para intereses individuales y de partido político. Estos movimientos de resistencia y acción social contra la gentrificación de la Ciudad de México están constituyendo un amplio frente de rechazo a la multiplicación de proyectos privatizadores.

Varias de estas organizaciones se han adscrito a la Plataforma Mexicana por el Derecho a la Ciudad y la Defensa del Territorio donde se expresó públicamente el 5 de octubre de 2015, Día 
Mundial del Hábitat, el interés común "Nos proponemos trabajar en la agenda con cuatro aspectos: 1) Reivindicación del espacio público para la participación social; 2) La defensa y ejercicio pleno del Derecho a la Ciudad y el Territorio; 3) La producción Social del Hábitat; y 4) Campaña 0 desalojos por megaproyectos. Planteamientos que deberían ser considerados como temas centrales de la tercera Conferencia de la Naciones Unidas sobre Vivienda y Desarrollo Sostenible, conocida como Hábitat III a realizarse en Quito, Ecuador, en octubre de 2016."

En el mismo encuentro se expresó la postura compartida: "Nuestro principal motivo de venir con ustedes es trazar una ruta de trabajo conjunta que permita que todos los barrios sometidos a la presión inmobiliaria y al desplazamiento de sus habitantes, convirtamos nuestras experiencias en el paradigma del derecho a la ciudad, arraigo y vivienda digna del siglo XXI". Pronunciamiento de vecinos de la Colonia Juárez contra la Zodes de Chapultepec, 5 de octubre de 2015.

Solo las acciones articuladas de las organizaciones ciudadanas y del movimiento urbano popular podrán detener los procesos de una gentrificación extendida y excluyente en la Ciudad de México.

\section{Referencias bibliográficas}

ABRAMO, P. La producción de las ciudades latinoamericanas: mercado inmobiliario y estructura urbana. Quito: OLACCHI, 2011.

BASAVE, J. y GUTIÉRREZ, M.T. Localización geográfica y sectores de inversión: factores decisivos en el desempeño de las multinacionales mexicanas durante la crisis. Journal of Economic, Finance \& Adm. Science, 2013, Vol. 18, N³4, p. 34-44.

CALIDAD DE VIDA, PROGRESO Y DESARROLLO PARA LA CIUDAD DE MÉXICO. Zodes Corredor Cultural Chapultepec- Zona Rosa. 2014. Disponible en Internet:

http://horizontal.mx/la-zode-chapultepec-operacion-inmobiliaria-espacio-publico-o-centro- comercial-privado/

CARRILLO, J. y GOMÍS, R. Un estudio sobre prácticas de empleo en firmas multinacionales en México: Un primer mapeo. Frontera Norte, 2011, Vol. 23, № 46, p. 35-60.

CÓCOLA, G.; DURÁN, G. y JANOSCHKA, M. La ciudad del siglo XXI: políticas públicas urbanas, desplazamientos y contestaciones. Iconos, 2016, № 56, p. 11-18.

CUENYA, B. y CORRAL, M. Empresarialismo, economía del suelo y grandes proyectos urbanos: el modelo de Puerto Madero en Buenos Aires. EURE, 2011, Vol. 37, № 111, p. 25 - 45.

DAHER, A. Territorios de la financiarización urbana y de las crisis inmobiliarias. Revista Geografía Norte Grande, 2013, №56, p.7-30.

DÍAZ, I. y SALINAS, L. La producción del consumidor. Valorización simbólica y gentrificación en el centro de la Ciudad de México. Andamios, 2016, Vol. 13, № 32, p. 107 - 130. 
GÓMEZ, L. Advierten sobre más expulsiones en la colonia Juárez, La Jornada, miércoles 2 de septiembre 2015. Disponible en Internet: http://www.jornada.unam.mx/2015/09/02/capital /035n3cap.

HARVEY, D. Espacios del capital. Hacia una geografía crítica. Madrid: Akal, 2001.

INEGI. Censo de población y vivienda 2010. Aguascalientes: INEGI, 2010.

INSTITUTO NACIONAL ELECTORAL (INE). Debate organizado por el Instituto Nacional Electoral sobre la Consulta Ciudadana del 6 de diciembre 2015. México: INE, 2015.

JARAMILLO, S. Hacia una teoría de la renta del suelo. Bogotá: Universidad de los Andes, 2009.

LEES, L.; SLATER, T. \& WYLY, E. Gentrification. New York: Routledge, 2008.

MARCUSE, P. Abandonment, gentrification, and displacement: the linkages in New York City. In: SMITH, N. \& WILLIAMS, P. (editors). Gentrification of the City. Londres: The City series, Routledge, 2002, p. 153-177.

METROS CÚBICOS. Alto nivel de plusvalía en el poniente del DF. 2013. Disponible en Internet: http://www.metroscubicos.com/articulo/guia-de-precios/2012/08/13/alto-nivel-de-plusvala- enel-poniente-del-df

MODONESI, M. Constructing the political subject. Subalternity, antagonism, autonomy. London: Pluto Press, 2014.

MORENO, L. The urban process under financialised capitalism. City: analysis of urban trends, culture, theory, policy, action, 2014, Vol. 18, №3, p. 244-268.

NEWMAN, K. \& WYLY, E. Gentrification and Resistance to displacement in New York City. Urban Studies, 2006, Vol. 43, № 1, p. 23-57.

OLIVERA, P. Neoliberalismo y gentrificación en ciudades norteamericanas. La Ciudad de México. En: OLIVERA, P. (editora). Polarización en la ciudad contemporánea. El re-escalamiento de los espacios del neoliberalismo. México: Facultad de Filosofía y Letras, UNAM, 2013, p. 79- 120.

OLIVERA, P. Neoliberalismo en la Ciudad de México: polarización y gentrificación. En: JANOSCHKA, M. e HIDALGO, R. (editores). La ciudad neoliberal. Gentrificación y exclusión en Santiago de Chile, Buenos Aires, Ciudad de México y Madrid. Santiago de Chile: GEOlibros Nº 19, Instituto de Geografía-Pontificia Universidad Católica de Chile y Universidad Autónoma de Madrid, 2014, p. 151- 177.

OLIVERA, P. y DELGADILLO, V. Políticas empresarialistas en los procesos de gentrificación en la ciudad de México. Revista de Geografía Norte Grande, 2014, № 58, p. 111-133. 
OLIVERA, P. La tematización como estrategia de consumo de la ciudad. En: GASCA, J. y OLIVERA, P. (editores). Ciudad, comercio urbano y consumo. Experiencias desde Latinoamérica y Europa. México: Instituto de Investigaciones Económicas-UNAM, 2017, p. 76-100.

PÉREZ, C. Colonia Juárez se desmorona. Diario de México, 2014. Disponible en Internet: http:// www.diariodemexico.com.mx/colonia-juarez-se-desmorona/

PRADILLA, E. Mundialización neoliberal, cambios urbanos y políticas estatales en América Latina. Cadernos Metrópole, 2010, Vol. 12, № 24, p. 507-533.

RAMÍREZ, T. M. Hidalgo: impugnan vecinos programa desarrollo urbano. La Jornada, 31 de agosto de 2005. Disponible en Internet: http://www.jornada.com.mx/2005/08/31/index.php?section=capital\&article=046n2cap

RODRÍGUEZ, M.C; RODRÍGUEZ, M.F. y ZAPATA, M. La casa propia, un fenómeno en extinción. La "inquilinización" en la ciudad de Buenos Aires. Cuadernos de Vivienda y Urbanismo, 2015, Vol. 8, $\left.N^{\circ} 15\right)$, p. 68-85.

SALINAS, L. La gentrificación de la colonia condesa, Ciudad de México. Aporte para una discusión desde Latinoamérica. Revista Geográfica de América Central, 2013, Vol. II, № 51, p. 116 - 138.

SALINAS, L. Transformaciones urbanas en el contexto neoliberal. La colonia Condesa en Ciudad de México: un proceso de gentrificación. Ci[ur] Cuadernos de Investigación Urbanística, 2014, № 93. Disponible en Internet:

http://polired.upm.es/index.php/ciur/article/view/2951/3011

SAMANIEGO, V. La Jornada, 21 de mayo de 2015, p. 32.

SEQUERA, J. A 50 años del nacimiento del concepto de "gentrificación". La mirada anglosajona. Biblio 3W. Revista Bibliográfica de Geografía y Ciencias Sociales, 2015, № 1.127, Disponible en Internet: http://www.ub.edu/geocrit/b3w-1127.pdf

SCHTEINGART, M. Sector inmobiliario capitalista y formas de apropiación del suelo: el caso de México. Demografía y Economía, 1979, Vol. XIII, N² 4, p. 449-466.

SMITH, N. New globalism, New Urbanism: Gentrification as Global Urban Strategy. In: BRENNER, N. \& THEODORE, N. Spaces of Neoliberalism, Oxford: Blackwell, 2002.

SUÁREZ, A. La función habitacional del Centro Histórico y los desafíos de su regeneración. En: Seminario Ciudad de México, PUEC-UNAM, México,2010.

TAMAYO, S. (coordinador). Los desafíos del Bando 2. Evaluación multidimensional del as políticas habitacionales en el Distrito Federal 2000-2006. México: SEDUVI, INVI, UACM, 2007.

WACQUANT, L. Relocating Gentrification: The Working Class, Science and the State in Recent Urban Research. International Journal of Urban and Regional Research, 2008, Vol. 32.1, p. 198-205. 
